\title{
EFFECTS OF HEPARIN ON THE LIPOPROTEINS IN HYPERLIPEMIA. AN ELECTROPHORETIC STUDY OF THE SERUM ALPHA AND BETA LIPOPROTEINS AFTER THEIR SEPARATION BY FRACTION- ATION OF THE PLASMA PROTEINS OR ULTRACEN- TRIFUGAL FLOTATION ${ }^{1}$
}

\author{
By FRANZ S. M. HERBST, WALTER F. LEVER, MARY E. LYONS, AND \\ NANCY A. HURLEY \\ (From the Department of Dermatology, Harzard Medical School, and the Dermatologic Re- \\ search Laboratory, Massachusetts General Hospital, Boston, Mass.)
}

(Submitted for publication October 22, 1954; accepted November 17, 1954)

The effects of heparin on the electrophoretic pattern of serum have recently been studied in this Laboratory. It had been found that in normal, strictly fasting individuals an intravenous injection of heparin caused no changes in the patterns obtained either by moving boundary electrophoresis or by paper electrophoresis $(1-4)$. On the other hand, in alimentary hyperlipemia and idiopathic hyperlipemia electrophoretic changes were observed. In the patterns obtained by moving boundary electrophoresis the changes consisted of a decrease in the beta- 1 globulins to a subnormal value and the appearance of a new component ahead of albumin $(1,2)$. On the basis of this observation it had been assumed that the pre-albumin component consisted of beta lipoproteins. However, subsequent studies by paper electrophoresis revealed that after an injection of heparin not only the beta lipoproteins but also the alpha lipoproteins showed an acceleration of their electrophoretic migration: The beta lipoprotein lipid band moved with the speed of either alpha-2 globulin, alpha-1 globulin, or intermediary between alpha-1 globulin and albumin and the alpha lipoprotein lipid band moved faster than albumin $(3,4)$.

Because the findings by paper electrophoresis indicated that the pre-albumin component consisted of the alpha lipoproteins and not of the betalipoproteins, as we had originally assumed, it was thought worth while to study in greater detail the effects of heparin on the alpha and beta lipo-

\footnotetext{
1 This investigation was supported by research grants from the National Institute of Arthritis and Metabolic Diseases, of the National Institutes of Health, Public Health Service (PHS A-414), and from the Milton Fund, Harvard University.
}

proteins after their separation from one another. Consequently, electrophoretic analyses were carried out on plasma protein fractions and on the lipoproteins isolated by ultracentrifugal flotation in 10 normal fasting persons, two persons with alimentary hyperlipemia and seven patients with idiopathic hyperlipemia before as well as one hour after an intravenous injection of $100 \mathrm{mg}$. of heparin.

\section{METHODS}

Collection of blood. Blood was withdrawn in a dry syringe, the samples were allowed to clot at room temperature, then centrifuged and the serum removed with a pipette. For the fractionation of the plasma proteins another blood sample was withdrawn in a syringe containing acid citrate-dextrose solution as an anticoagulant (5).

Electrophoresis. Paper electrophoresis was carried out, as described in our previous communications $(3,4)$, according to the technique of Grassmann and Hannig (6) with subsequent staining of the proteins with Amido Black 10B, and of the lipids with Sudan Black B $(7,8)$. For the quantitative determination of the relative amounts of protein the paper strips stained for protein were immersed for half an hour in a mixture of alpha bromnaphthalene and paraffin oil. This produced sufficient clearing of the paper strips so that they could be read in a densitometer. The diagram thus obtained was analyzed by planimetry. Quantitative determination of the relative amounts of lipids on the lipid stained paper strips gave variable and unreliable results which therefore are not reported.

Moving boundary electrophoresis was performed in a Perkin-Elmer Tiselius electrophoresis apparatus, Model 38 , as described in previous communications $(3,9)$.

Fractionation. Fractionation of the plasma proteins was carried out according to Method 10 of Cohn and his co-workers (10), modified for small amounts of plasma by Lever and his co-workers (5). Two main fractions were obtained, Fraction I + II + III, containing the beta lipoproteins, and Fraction IV $+\mathrm{V}$, containing the alpha lipoproteins. Since Fraction I + II + III contained 
fibrinogen, which on analysis by paper electrophoresis interacts with the supporting medium, two drops of a thrombin solution containing 200 N.I.H. units per $\mathrm{ml}$. were added to the fraction, following which the fibrin clot was removed. Electrophoretic analysis was carried out on the two main fractions within twenty-four hours after the fractionation of the plasma.

Preparative ultracentrifugation. Spinco Model L was used as preparative ultracentrifuge. The rotor was Spinco Model No. 40 in which the tubes are fixed at an angle of 26 degrees. Centrifugation was carried out at 16 C. for approximately fifteen hours at a speed of 35,000 R.P.M. which is equivalent to a gravitational force of $80,730 \mathrm{G}$.

For preparative ultracentrifugation at a solution density of $1.063 \mathrm{Gm}$. per $\mathrm{ml}$. $3 \mathrm{ml}$. of serum were mixed with $7 \mathrm{ml}$. of a sodium chloride-water solution of such density to give a final density of $1.063 \mathrm{Gm}$. per $\mathrm{ml}$. at $26 \mathrm{C}$. After centrifugation the uppermost $1 \mathrm{ml}$. containing the low density lipoproteins, or beta lipoproteins, was then pipetted off (11).

For preparative ultracentrifugation at a solution density of $1.21 \mathrm{Gm}$. per $\mathrm{ml} .3 \mathrm{ml}$. of serum were mixed with $7 \mathrm{ml}$. of a potassium bromide-water solution of such density to give a final density of $1.21 \mathrm{Gm}$. per ml. at $26 \mathrm{C}$. After centrifugation the uppermost $1 \mathrm{ml}$. was pipetted off. In it were present the low as well as the high density lipoproteins, i.e., the alpha and beta lipoproteins $(12,13)$.

Paper electrophoresis of the isolated lipoproteins was carried out within twenty-four hours after ultracentrifugation.

\section{RESULTS}

\section{Plasma fractions}

Fasting normal persons. Fraction IV $+\mathrm{V}$ on analysis by paper electrophoresis and subsequent staining for proteins contained, just as on analysis by moving boundary electrophoresis $(10,5)$, most of the albumin of the serum, most of the alpha- 1 globulins, and small amounts of the alpha-2 and beta' globulins (Figure 1). On the paper strips stained for lipids one lipid band was present in the alpha-1 globulin area representing the alpha lipoproteins.

Fracticn I + II + III showed on the paper strips stained for proteins, just as on moving boundary electrophoresis, small amounts of albumin, most of the alpha- 2 and beta globulins and all the gamma globulin (Figure 2). Paper strips stained for lipids showed one lipid band in the beta-1 globulin area representing the beta lipoproteins.

Injection of heparin into 10 normal fasting persons caused no changes in the paper electropho-

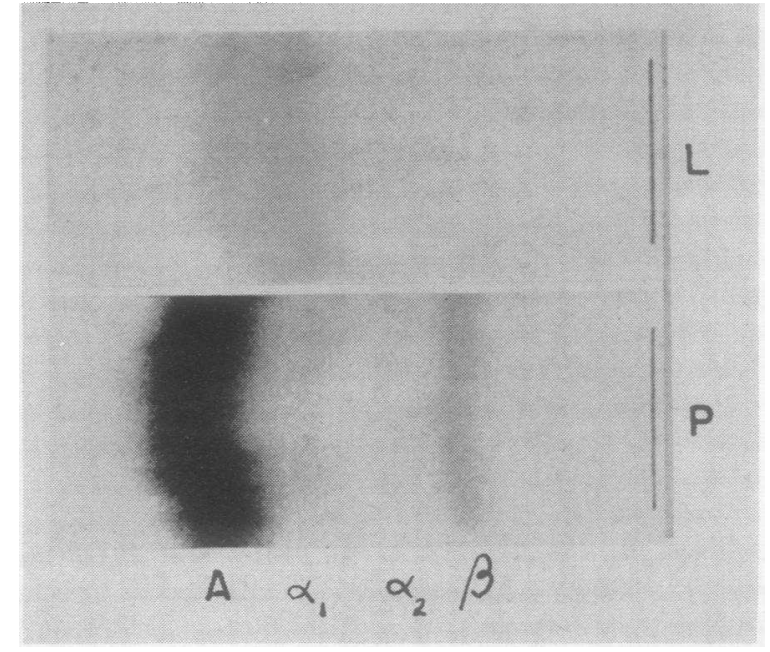

Fig. 1. Paper Electrophoretic Patterns of the Aipha Lipoprotein Fraction (Fraction IV $+\mathrm{V}$ ) of a Normal Individual

On the lipid stained paper strip (L) one band is present in the alpha-1 globulin area, representing the alpha lipoproteins.

retic patterns of either Fraction $\mathrm{IV}+\mathrm{V}$ or Fraction I + II + III.

Idiopathic hyperlipemia. Analysis of Fraction $\mathrm{IV}+\mathrm{V}$ (alpha lipoprotein fraction) by paper electrophoresis and subsequent staining for proteins and lipids in seven patients with idiopathic hyperlipemia revealed a normal pattern. One

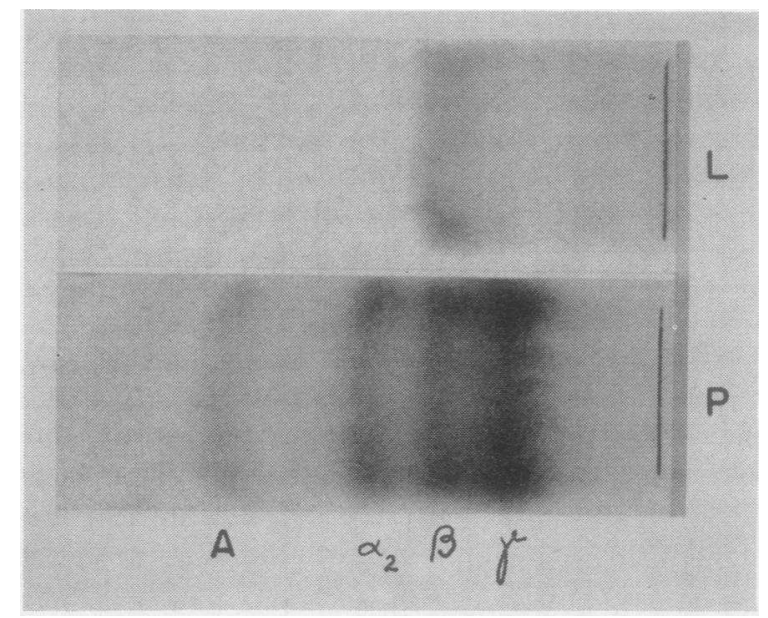

Fig. 2. Paper Electrophoretic Patterns of the Beta Lipoprotein Fraction (Fraction I + II + III) of a Normal Individual.

On the lipid stained paper strip (L) one band is present in the beta globulin area, representing the beta lipoproteins. 


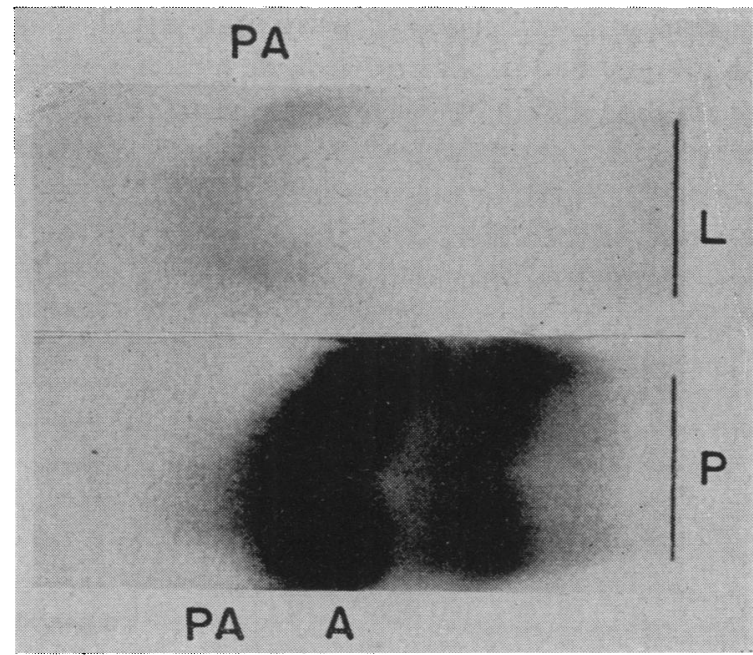

Fig. 3. Paper Electrophoretic Patterns of the Alpha Lipoprotein Fraction (Fraction IV $+\mathrm{V}$ ) of a Patient with Idiopathic Hyperlipemia after an InTRAvenous InJection of 100 Mg. OF Heparin

The alpha lipoprotein band on the lipid stained paper strip (L) moves faster even than albumin as a pre-albumin component (PA). The protein stained paper strip (P) shows that the pre-albumin component contains a small amount of protein.

hour after the intravenous injection of $100 \mathrm{mg}$. of heparin, staining for lipid revealed that the one lipid band present (alpha lipoprotein) had in- creased its speed of migration and migrated ahead of albumin (Figure 3). The protein stained paper strip showed that this pre-albumin component contained small amounts of protein. Analysis of Fraction IV $+\mathrm{V}$ by moving boundary electrophoresis also showed the pre-albumin component (Figure 4).

Analysis of Fraction I + II + III (beta lipoprotein fraction) by paper electrophoresis and subsequent staining for proteins revealed a greater intensity of staining of the beta globulin band than in normal fasting persons. On staining for lipids the lipid band present in the beta globulin area (beta lipoprotein) stained much more intensely than normal. Furthermore, just as in the patterns obtained on whole serum (4), the beta lipoprotein band showed a densely stained trail extending back to the starting line. This trail was due mainly to the chylomicra. One hour after the injection of heparin, the trail of the beta lipoprotein band showed a considerable decrease in its staining intensity and the beta lipoprotein band itself moved with the speed of alpha- 2 or even alpha-1 globulin (Figure 5). The protein stained paper strip showed a small amount of protein moving with the same increased speed as the beta lipoprotein on the lipid stained paper, repre-

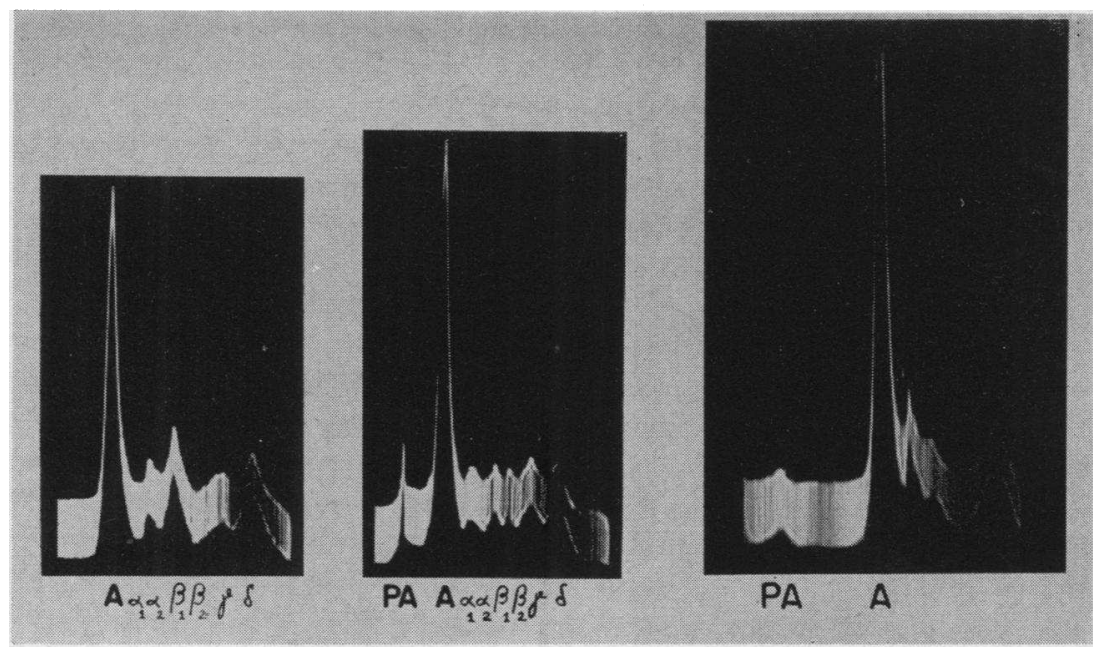

Fig. 4. Patterns Obtained by Moving Boundary Electrophoresis in a Patient With Idiopathic Hyperlipemia

Left, fasting serum: the alpha- 2 peak is slightly and the beta-1 peak is moderately elevated. Middle, serum after an intravenous injection of $100 \mathrm{mg}$. of heparin : the beta-1 peak has decreased to a subnormal size and a new component has appeared ahead of albumin (PA). Right, alpha lipoprotein fraction (Fraction IV + V) after an intravenous injection of heparin: The pre-albumin component (PA) is present in this fraction. 


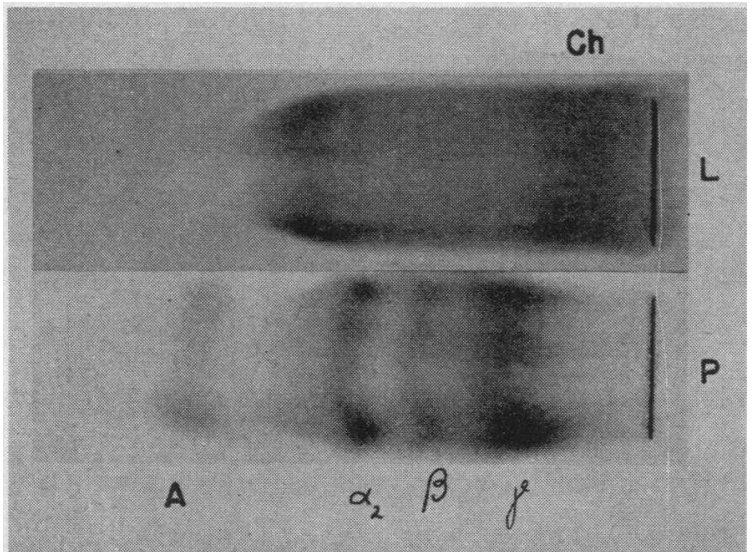

Fig. 5. Paper Electrophoretic Patterns of the Beta Lipoprotein Fraction (Fraction I + II + III) of a Patient with Idiopathic Hyperlipemia After an Intravenous Injection of $100 \mathrm{Mg}$. OF Heparin

The beta lipoprotein band on the lipid stained paper strip (L) moves with the speed of alpha-1 globulin.

senting the protein moiety of the beta lipoproteins. Satisfactory patterns by the moving boundary method could not be obtained because of the milky appearance of Fraction I + II + III, caused by the presence of large amounts of chylomicra.

\section{Isolated lipoproteins}

Fasting normal persons. Paper electrophoresis carried out on the lipoproteins isolated by ultra-

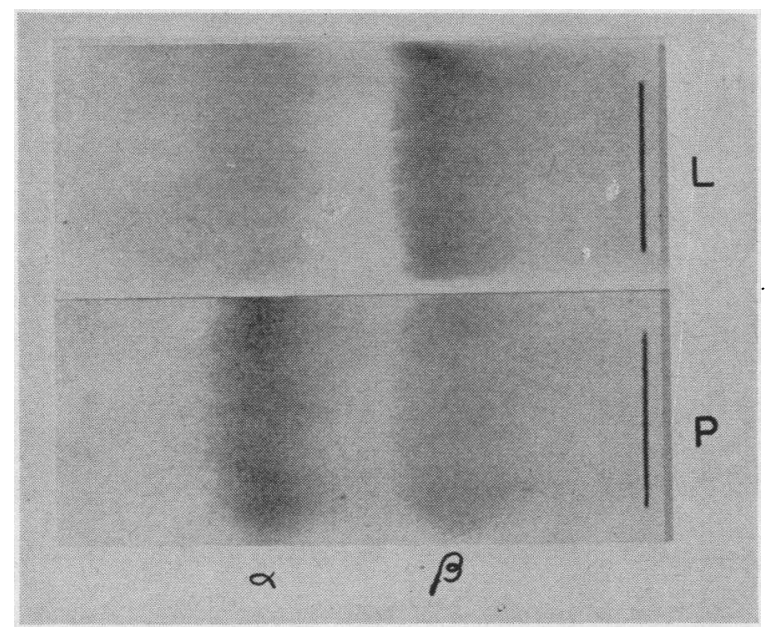

Fig. 6. Paper Electrophoretic Patterns of the Lipoproteins of a Normal INDIVIDUAL IsOlated BY Ultracentrifugal Flotation at a Density of 1.21 GM. PER ML.

Two bands representing the alpha and beta lipoproteins, respectively, are present on the lipid stained (L) as well as on the protein stained (P) paper strip. centrifugal flotation at a density of $1.21 \mathrm{Gm}$. per ml. showed two bands on the lipid stained as well as on the protein stained paper strip indicating the presence of both the alpha and beta lipoproteins (Figure 6). Comparison of the lipid stained paper strip with the one stained for proteins confirmed the fact, established already by chemical analysis (14), that the alpha lipoproteins have a relatively low lipid-protein ratio in contrast to the beta lipoproteins which have a high lipid-protein ratio.

Paper electrophoresis of the lipoproteins isolated by flotation at a density of $1.063 \mathrm{Gm}$. per ml. showed only one band on the protein and lipid stained paper strips representing the beta lipoproteins (Figure 7). Again the relatively high lipid-protein ratio of the beta lipoproteins was apparent.

Injection of heparin into 10 fasting normal persons did not cause any changes in the electrophoretic patterns.

Idiopathic hyperlipemia. Analysis by paper electrophoresis of the lipoproteins floated at a density of $1.21 \mathrm{Gm}$. per ml. (alpha and beta lipoproteins) revealed two distinct bands on both the protein and lipid stained paper strips representing the alpha and beta lipoproteins, respectively. The intensity of staining of the beta lipoproteins was greater than normal on the protein stained

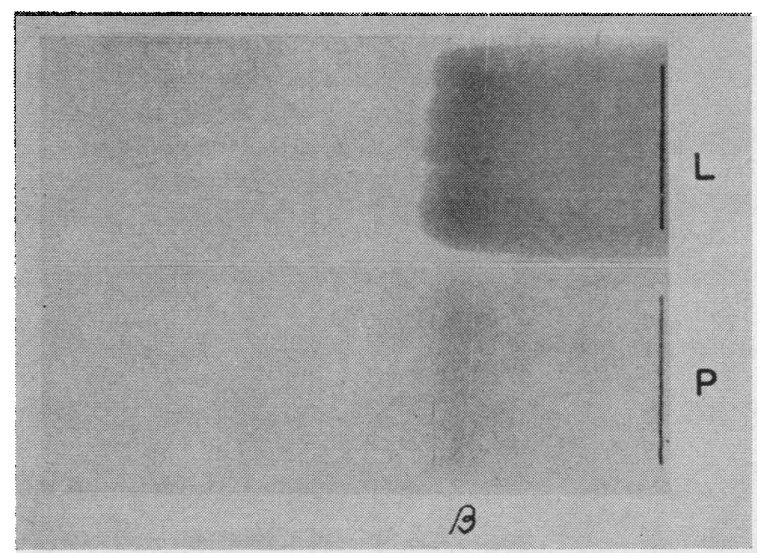

Fig. 7. Paper Electrophoretic Patterns of the Lipoproteins OF A NoRMal INDIVIdUAL IsOlated BY Ultracentrifugal Flotation at a Density of 1.063 GM. PER ML.

One band representing the beta lipoproteins is present on the lipid stained (L) and on the protein stained (P) paper strips. 
as well as on the lipid stained paper strip. As in the analysis of whole serum and of Fraction I + II + III, the lipid stained paper strip but not the protein stained paper strip showed considerable trailing of the beta lipoprotein band, due to the chylomicra.

Analysis of the lipoproteins floated at a density of $1.063 \mathrm{Gm}$. per $\mathrm{ml}$. (beta lipoproteins) revealed the same patterns as just described except that no alpha lipoprotein band was present.

An injection of heparin caused the following changes in the lipoproteins floated at a density of $1.21 \mathrm{Gm}$.per $\mathrm{ml}$. (alpha and beta lipoproteins) : On the lipid stained paper strip the alpha lipoprotein band appeared much broader than before and the trail of the beta lipoprotein band representing the chylomicra showed a decrease in its staining intensity. On the protein stained paper strip three bands were now present instead of two bands (Figure 8). Comparison of the protein stained with the lipid stained paper strip indicated that only the slowest moving of the three bands on the protein stained paper strip corresponded to the beta lipoproteins, whereas the two faster moving bands corresponded to the alpha lipoproteins. That the two faster moving bands represented the alpha lipoproteins and only the third, slowest moving band represented the beta lipoproteins was definitely proven by analysis of the beta lipoproteins floated at a density of $1.063 \mathrm{Gm}$. per $\mathrm{ml}$. since paper electrophoresis of the beta lipoproteins thus obtained showed only one band on the protein and lipid stained paper strips corresponding to the slowest moving band.

In order to obtain information to which extent heparin had caused an increase in the speed of electrophoretic migration of the lipoproteins, blood was obtained before and after the injection of heparin and the lipoproteins were isolated by flotation at a density of $1.21 \mathrm{Gm}$. per $\mathrm{ml}$. They then were analyzed side by side in the same electrophoresis chamber and both paper strips were stained for proteins. Comparison of the preheparin sample with the post-heparin sample revealed after the administration of heparin an increase in the electrophoretic mobility of the alpha as well as of the beta lipoproteins (Figure 8). The alpha lipoprotein band had split up into two bands of which the slower band showed only a

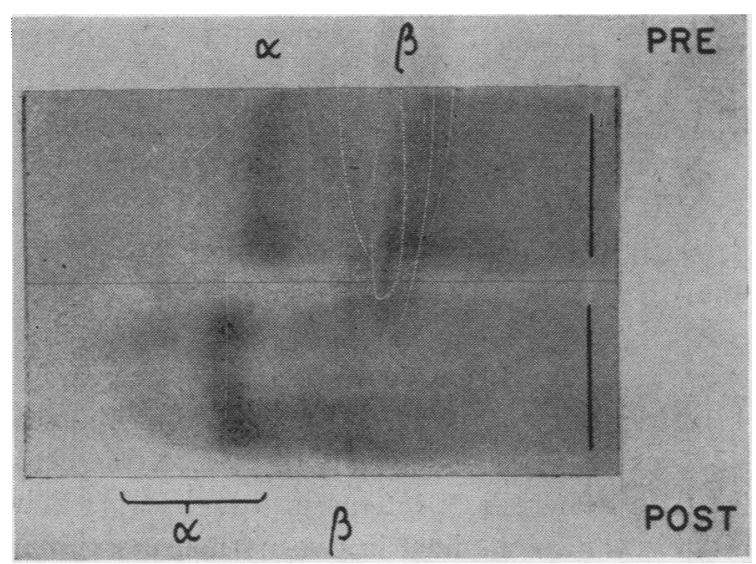

Fig. 8. Paper Electrophoretic Patterns (Stained for Proteins) of the Lipoproteins of a Patient with IDIOPATHIC HYPERLIPEMIA BEFORE (PRE) AND AFTER (POST) aN Intravenous InJection OF Heparin

The lipoproteins were isolated by ultracentrifugal flotation at a density of $1.21 \mathrm{Gm}$. per $\mathrm{ml}$. The pre-heparin and post-heparin samples were analyzed simultaneously. The alpha lipoproteins in the post-heparin sample are split up into two components. Both alpha lipoprotein bands as well as the beta lipoprotein band show an increase in their electrophoretic mobility following the injection of heparin.

slight increase in mobility, was narrow and well stained, while the faster band was broad and faintly stained.

Alimentary hyperlipemia. Two normal persons in an alimentary hyperlipemic state were studied. They had received a meal consisting of $480 \mathrm{ml}$. of heavy cream, $32 \mathrm{Gm}$. of sugar and $16 \mathrm{Gm}$. of cocoa. Three and a half hours after the meal 100 $\mathrm{mg}$. of heparin were injected intravenously. Analysis by paper electrophoresis of the plasma fractions and of the isolated lipoproteins before and after heparin gave the same results as in idiopathic hyperlipemia, except that the beta lipoproteins on the protein-stained as well as on the lipid stained paper strip showed a normal staining intensity.

\section{Determination of the relative distribution of pro- teins between alpha and beta lipoproteins}

The alpha and beta lipoproteins of the serum were isolated by flotation at a density of $1.21 \mathrm{Gm}$. per $\mathrm{ml}$. before and after an injection of heparin. They then were analyzed by paper electrophoresis and the paper strips were stained for protein.

Determination of the relative amounts of pro- 
tein present in the alpha and beta lipoprotein bands of the paper strips revealed in 10 fasting normal individuals, on the average, 74 per cent of the proteins as alpha lipoproteins and 26 per cent as beta lipoproteins (range of variation 24 to 27 per cent). The average values in seven patients with idiopathic hyperlipemia revealed a considerably higher percentage of proteins in the beta lipoprotein band than in normal persons, namely 42 instead of 26 per cent (range of variation 36 to 51 per cent). This was indicative of the great increase in beta lipoproteins in this disease. The relative values obtained in two normal individuals in an alimentary hyperlipemic state were the same as in normal fasting persons.

Injection of heparin into 10 normal persons, seven patients with idiopathic hyperlipemia and two normal persons in an alimentary hyperlipemic state caused no changes in the distribution of proteins between the alpha and beta lipoproteins in any of the cases.

\section{DISCUSSION}

For a study of the action of heparin on the lipoproteins of normal and hyperlipemic sera two methods were employed by us: Separation of the alpha lipoproteins from the beta lipoproteins by chemical fractionation, and isolation of the two lipoproteins by ultracentrifugal flotation at densities of 1.063 and $1.21 \mathrm{Gm}$. per $\mathrm{ml}$. These two methods in conjunction with analysis by paper electrophoresis proved very useful since they enabled us to study the effects of heparin on the alpha and beta lipoproteins separately. The analyses by paper electrophoresis showed that fractionation of the plasma proteins by the smallscale modification of Cohn's Method 10 resulted in a clear-cut separation of the alpha lipoproteins from the beta lipoproteins since each was present in one fraction exclusively. Even after the injection of heparin complete separation of the two lipoproteins was obtained.

\section{Effects of heparin on the electrophoretic mobility of the lipoproteins}

Injection of heparin caused no change in the electrophoretic mobility of the separated or isolated lipoproteins in normal individuals. On the other hand, in persons with either alimentary or idiopathic hyperlipemia both the alpha and beta lipoproteins showed an increase in their electrophoretic mobility. Of especial interest were the findings on chemical fractionation where after the injection of heparin the beta lipoproteins on the paper strip used for the analysis of Fraction I + II + III moved with the speed of alpha-2 or alpha-1 globulin. while the alpha lipoproteins on the paper strip used for the analysis of Fraction $I V+V$ moved faster than albumin. This provided conclusive evidence that the pre-albumin component which we had observed following the injection of heparin in the electrophoretic patterns of whole serum in idiopathic hyperlipemia $(1,2)$ as well as in alimentary hyperlipemia (3) represented the alpha lipoproteins.

\section{Does heparin cause a transformation of beta into alpha lipoproteins?}

Several authors (15-19) have expressed the opinion that heparin causes a transformation of beta lipoproteins into alpha lipoproteins. Boyle. Bragdon, and Brown (15), carrying out ultracentrifugal analyses at a density of $1.21 \mathrm{Gm}$. per ml., observed in alimentary hyperlipemia on injection of heparin and subsequent in vitro incubation of the plasma an increase in the $\mathrm{S}_{\mathrm{f}}$ classes representing the alpha lipoproteins. Nikkilä (18). who also made in vivo studies, found by analysis with moving boundary and paper electrophoresis an increase in the amount of the alpha lipoprotein lipids in alimentary hyperlipemia following the injection of heparin. This observation, however. merely indicates that the beta lipoproteins migrated with the speed of the alpha lipoproteins and does not indicate an actual transformation of beta lipoproteins into alpha lipoproteins. ${ }^{2}$

2 The fact that Nikkilä observed no pre-albumin component in alimentary hyperlipemia after the injection of heparin may be due to the fact that he gave smaller amounts of cream $(200 \mathrm{ml}$.) than we did $(480 \mathrm{ml}$.) for the purpose of inducing alimentary hyperlipemia and consequently only the beta lipoproteins but not the alpha lipoproteins showed an increase in the speed of electrophoretic migration. This would be analogous to an observation which we made on two individuals whom we had presumed to be fasting but who had not been strictly fasting (2). On moving boundary electrophoresis we observed in both persons a decrease in the beta-1 globulin peak from normal to subnormal values together with an increase in the alpha- 2 peak in one and in the alpha-1 peak in the other. There was no pre-albumin peak present in either of these two persons. 
The following are our reasons for believing that an in vivo transformation of beta lipoproteins into alpha lipoproteins by heparin does not occur: First, analysis of whole serum by paper electrophoresis and subsequent staining for lipids never showed an increase in the staining intensity of the alpha lipoprotein band after the injection of heparin either in alimentary hyperlipemia (3) or idiopathic hyperlipemia (4). Second, as shown in the present study, isolation of the two lipoproteins by ultracentrifugal flotation followed by paper electrophoresis and staining for proteins showed after the injection of heparin neither in alimentary nor in idiopathic hyperlipemia any change in the distribution of the proteins between alpha and beta lipoproteins. Third, chemical fractionation of the plasma proteins by Cohn's Method 10 and determination of the amounts of cholesterol and phospholipids present as alpha lipoproteins and beta lipoproteins in idiopathic hyperlipemia never revealed abnormally high amounts of lipids in the alpha lipoprotein fraction either after a single injection or after the long-term administration of heparin; whereas the elevated values for cholesterol and phospholipids in the beta lipoprotein fraction decreased $(1,20)$. Fourth, heparin was found to exert no effect on beta lipoproteins with $S_{t}$ values below 12 (21). Although beta lipoproteins with high $S_{\mathbf{f}}$ values were successively transformed into beta lipoproteins with lower $S_{f}$ values but slight changes only occurred in those normal individuals whose serum contained solely beta lipoproteins with $S_{f}$ values of 20 and below; and no changes took place in normal individuals who had only beta lipoproteins with $S_{\mathfrak{f}}$ values below 12 . Since the gradual transformation of the low density beta lipoproteins into those of higher density stops after the beta lipoproteins have incurred a certain increase in density it seems unlikely that the beta lipoproteins could change all the way into high density alpha lipoproteins.

\section{Cause of the increase in electrophoretic mobility of the alpha and beta lipoproteins after heparin}

According to our present knowledge heparin has a direct effect only on beta lipoproteins of high $S_{f}$ values causing their transformation into those of lower $S_{\boldsymbol{f}}$ values, but apparently has no effect on beta lipoproteins of low $S_{\boldsymbol{p}}$ values and on the alpha lipoproteins. How then does heparin cause an increase in the electrophoretic mobility of the alpha as well as of the beta lipoproteins in hyperlipemic sera? It appears likely that these electrophoretic changes are a secondary effect of the action of heparin on the beta lipoproteins with high $S_{p}$ values. Shore, Nichols, and Freeman (22) observed that in vivo heparinized plasma caused a release of fatty acids from beta lipoproteins provided they were obtained from lipemic sera and thus possessed high $S_{t}$ values. Furthermore, Gordon (23) by the in vitro addition of oleate to normal serum produced an increase in the mobility of the alpha and beta lipoproteins.

If one assumes that the increase in the electrophoretic mobility of the alpha and beta lipoproteins after an injection of heparin is due to the binding of fatty acids by these lipoproteins, as suggested by Gordon's study, one could explain not only the increased mobility of both lipoprotein classes in persons with hyperlipemia but also the absence of electrophoretic changes in strictly fasting normal persons. Fasting serum contains beta lipoproteins of low $S_{\boldsymbol{f}}$ values only. Thus very small amounts of fatty acids are available for release by heparin. On the other hand, hyperlipemic serum contains large amounts of beta lipoproteins with high $S_{t}$ values and accordingly. large amounts of fatty acids (24). Some of these fatty acids are released after an injection of heparin and then bound to the beta lipoproteins of low $S_{\mathfrak{f}}$ values as well as to the alpha lipoproteins, thus increasing the electrophoretic mobility of these lipoproteins.

\section{SUMMARY}

1. The action of heparin on the serum alpha and beta lipoproteins in idiopathic and alimentary hyperlipemia was studied by electrophoretic analyses of these two lipoproteins after their separation by chemical fractionation as well as after their isolation by ultracentrifugal flotation at densities of 1.063 and $1.21 \mathrm{Gm}$. per $\mathrm{ml}$.

2. Electrophoretic analysis of the alpha and beta lipoproteins after their chemical separation revealed in both types of hyperlipemia as the result of an intravenous injection of heparin an increase in the electrophoretic mobility of both lipoproteins. The separated alpha lipoproteins moved 
faster than albumin and the separated beta lipoproteins moved with the speed of either alpha-2 or alpha-1 globulin.

3. Electrophoretic analysis of the alpha and beta lipoproteins after their isolation by ultracentrifugal flotation also revealed an increase in their electrophoretic mobility following the injection of heparin. The alpha lipoproteins were present as two components in the post-heparin patterns obtained by paper electrophoresis.

4. These studies allow the conclusion that the pre-albumin component which we had observed following the injection of heparin in the electrophoretic patterns of whole serum in idiopathic as well as alimentary hyperlipemia represents the alpha lipoproteins.

5. No evidence was found in this study as well as in our previous studies to support the recently proposed concept that the administration of heparin causes a transformation of beta lipoproteins into alpha lipoproteins.

6. The increase in the electrophoretic mobility of the alpha and beta lipoproteins in hyperlipemia following the administration of heparin may be explained by the lipolytic effect of heparin and the resultant binding of fatty acids by the alpha and beta lipoproteins.

\section{REFERENCES}

1. Lever, W. F., Smith, P. A. J., and Hurley, N. A., Effects of intravenous heparin on the plasma lipoproteins in primary hypercholesteremic xanthomatosis and idiopathic hyperlipemia. Science 1953, $118,653$.

2. Lever, W. F., Smith, P. A. J., and Hurley, N. A., Idiopathic hyperlipemia and primary hypercholesteremic xanthomatosis. III. Effects of intravenously administered heparin on the plasma proteins and lipids. J. Invest. Dermat., 1954, 22, 71.

3. Herbst, F. S. M., and Hurley, N. A., Effects of heparin on alimentary hyperlipemia. An electrophoretic study. J. Clin. Invest., 1954, 33, 907.

4. Herbst, F. S. M., Lever, W. F., and Hurley, N. A., Idiopathic hyperlipemia and primary hypercholesteremic xanthomatosis. VI. Studies of the serum proteins and lipoproteins by moving boundary electrophoresis and paper electrophoresis before and after administration of heparin. J. Invest. Dermat., In press.

5. Lever, W. F., Gurd, F. R. N., Uroma, E., Brown, R. K., Barnes, B. A., Schmid, K., and Schulz, E. L., Chemical, clinical, and immunological studies on the products of human plasma fractionation. XL.
Quantitative separation and determination of the protein components in small amounts of normal human plasma. J. Clin. Invest., 1951, 30, 99.

6. Grassmann, W., and Hannig, K., Ein quantitatives Verfahren zur Analyse der Serumproteine durch Papierelektrophorese. Hoppe-Seyler's Ztschr. f. physiol. Chem., 1952, 290, 1.

7. Swahn, B., A method for localization and determination of serum lipids after electrophoretical separation on filter paper. Scandinav. J. Clin. \& Lab. Invest., 1952, 4, 98.

8. Swahn, B., Studies on blood lipids. Scandinav. J. Clin. \& Lab. Invest., 1953, vol. 5, suppl. 9.

9. Lever, W. F., Smith, P. A. J., and Hurley, N. A., Idiopathic hyperlipemia and primary hypercholesteremic xanthomatosis. II. Analysis of the plasma proteins and lipids by means of electrophoresis and fractionation of the plasma proteins; Effect of high speed centrifugation and of extraction with ether on the plasma proteins and lipids. J. Invest. Dermat., 1954, 22, 53.

10. Cohn, E. J., Gurd, F. R. N., Surgenor, D. M., Barnes, B. A., Brown, R. K., Derouaux, G., Gillespie, J. M., Kahnt, F. W., Lever, W. F., Liu, C. H., Mittelman, D., Mouton, R. F., Schmid, K., and Uroma, E., A system for the separation of the components of human blood: Quantitative procedures for the separation of the protein components of human plasma. J. Am. Chem. Soc., 1950, 72, 465.

11. De Lalla, O. F., and Gofman, J. W., Ultracentrifugal analysis of serum lipoproteins in Methods of Biochemical Analysis, ed. by David Glick, New York, Interscience Pbl., 1954, vol. I, p. 459.

12. Gofman, J. W., Lipoprotein transformations in health and disease. Educational Proc. Permanente Hospitals, 1952, 2, 174.

13. Green, A. A., Lewis, L. A., and Page, I. H., A method for the ultracentrifugal analysis of alpha and beta serum lipoproteins. Federation Proc., 1950, 10, 191.

14. Oncley, J. L., and Gurd, F. R. N., The lipoproteins of human plasma in Blood Cells and Plasma Proteins, ed. by James E. Tullis, New York, N. Y., Academic Press, 1953, p. 337.

15. Boyle, E., Bragdon, J. H., and Brown, R. K., Role of heparin in in vitro production of alpha-1 lipoproteins in human plasma. Proc. Soc. Exper. Biol. \& Med., 1952, 81, 475.

16. Brown, R. K., Boyle, E., and Anfinsen, C. B., The enzymatic transformation of lipoproteins. J. Biol. Chem., 1953, 204, 423.

17. Williams, G. R., Lipoprotein transformations under the influence of heparin and Clostridium Welchii alpha-toxin. Biochim. et Biophys. Acta, 1954, 13, 72.

18. Nikkilä, E., Studies on the lipid-protein relationships in normal and pathological sera and the effect of 
heparin on serum lipoproteins. Scandinav. J. Clin. \& Lab. Invest., 1953, Vol. 5, Suppl. 8.

19. Nikkilä, E., and Gräsbeck, R., Heparin in lipoid nephrosis. Observations of the effects on edema, proteinuria, serum proteins, lipids and lipoproteins. Acta med. Scandinav., 1954, 150, 39.

20. Lever, W. F., Herbst, F. S. M., and Hurley, N. A., Idiopathic hyperlipemia and primary hypercholesteremic xanthomatosis. IV. Effect of prolonged administration of heparin on serum lipids in idiopathic hyperlipemia. Arch. Dermat., 1955, 71, 150.

21. Lever, W. F., Herbst, F.S.M., and Lyons, M. E., Idiopathic hyperlipemia and primary hypercholesteremic xanthomatosis. V. Analysis of serum lipoproteins by means of ultracentrifuge before and after administration of heparin. Arch. Dermat., 1955, 71, 158.

22. Shore, B., Nichols, A. V., and Freeman, N. K., Evidence for lipolytic action by human plasma obtained after intravenous administration of heparin Proc. Soc. Exper. Biol. \& Med., 1953, 83, 216.

23. Gordon, R. S., Interaction between oleate and the lipoproteins of human serum. J. Clin. Invest., In press.

24. Jones, H. B., Gofman, J. B., Lindgren, F. T., Lyon, T. P., Graham, D. M., Strisower, B., and Nichols, A. V., Lipoproteins in atherosclerosis. Am. J. Med., 1951, 11, 358. 